\title{
First Steps of the History of Chinese Philosophy in China
}

\author{
Valery A. Kiselev \\ Candidate of Science in Philosophy, associate Professor \\ People's Friendship University of Russia (RUDN University) \\ 6 Miklukho-Maklaya St., Moscow, 117198, Russian Federation \\ E-mail: kiselev_va@rudn.university
}

\begin{abstract}
Chinese philosophy begins in ancient and archaic times, but if we make a scrupulous research, we find that real Chinese philosophy begins only in the beginning of the 20th century, when Japanese translation of the word "philosophy" zhexue - came to China, and Chinese scholars began to create histories of Chinese philosophy. In the first part of the 20th century a number of "histories of Chinese philosophy" was created. Most influential of them were "Outline of the History of Chinese Philosophy" by $\mathrm{Hu}$ Shih and "History of Chinese Philosophy" by Feng Youlan. These works formed our modern understanding of Chinese philosophy, made Chinese philosophy more accessible to the Western readers, but at the same time, served as basis for doubts as to whether there was Chinese philosophy in itself, or it was only a stereotyped exposition of traditional Chinese thought by means of the system of Western terms.
\end{abstract}

Keywords-Chinese philosophy; History of Chinese philosopy; Xie Wuliang; Hu Shih; Feng Youla

\section{INTRODUCTION}

Controversy about whether there was a philosophy in China or not does not stop probably from the very moment the West met with Chinese civilization. The authors of the first works on Chinese thought in the West did not doubt that they are dealing with philosophy (F.e. Matteo Ricci and Nicolas Trigault in "De Christiana expeditione apud Sinas" referred to Confucius as "the greatest philosopher of all the Chinese". Translation of the Confucian classics in 1687 was named "Confucius Sinarum philosophus "), while Hegel unequivocally denied Chinese thought a chance to be a philosophy [1. P. 117-125]. At the present time we see that on the one hand there are a lot of books about Chinese philosophy, scientific seminars and conferences devoted to it, but at the same time there are researchers who are wondering whether Chinese philosophy can be considered a philosophy.

Because of an unprecedented pressure of the Western civilization in the late 19th and early 20th centuries, China lost some of its sovereignty and faced the need for modernization to preserve the existence of the country. Even the first attempts at modernization showed that it is impossible to borrow only technology, it is necessary to revise the entire Chinese culture. A long and difficult period of integration of Western civilization norms into Chinese culture began, and this process

The publication was prepared with the support of the "RUDN University Program 5-100" also included mutual integrational work in the field of philosophy.

The creation of "histories of Chinese philosophy" in the first half of the 20th century was aimed at confirming the philosophical status of Chinese thought, which was an important part of the work of Chinese intellectuals to affirm China's right to a dignified place among world powers.

The first work on the history of Chinese philosophy, written by a Chinese scientist, was the book "The History of Chinese Philosophy" by Xie Wuliang. This work shows the desire of the scientist not only to expound the history of Chinese thought, but also to show to the Chinese reader that even though the word "philosophy" is of Western origin, which "was translated in China ", nevertheless, Chinese thought is a full-fledged philosophy, equivalent to the western one. Xie Wuliang notes that from a very ancient time Chinese philosophy dealt with the same issues as the Western philosophy, in Chinese philosophy there were the same categories, the content of the discussions in these philosophies also coincides. At the same time, Xie Wuliang writes that "Fu $\mathrm{Xi}$ laid the original foundations of ancient and modern philosophy" [2], thus giving an idea, that Chinese philosophy originated earlier than the West

Contemporaries criticized this work for the fact that it was not an independent research, but a transposition of the "Sina tetsugaku si" (支那哲学史) by Japanese scientist Takase Takejiro (高瀬武次郎, 1869-1950), and for the fact that this work is far from the ideals of science, and is only retelling of traditional myths and explains the canons with the help of canons.

In the 20-40s of the 20th century, a number of works on the history of Chinese philosophy were published in China, and the first of them Hu Shih's "Outline of the History of Chinese Philosophy” (中国哲学史大纲) and Feng Youlan's “History of Chinese Philosophy” (中国哲学史) overshadowed the work of Xie Wuliang. 


\section{Hu SHIH AND FENG YoulAn: DifFERENT APPROACHES} TO THE BASICS OF THE PHILOSOPHY

Both $\mathrm{Hu}$ Shih and Feng Youlan completed their philosophical education in the United States at Columbia University, the famous American pragmatist John Dewey (1859-1952) was their dissertation chairman. After returning to China, each of them published a study on the history of Chinese philosophy: "Outline of the history of Chinese philosophy" by Hu Shih in 1919, and in 1931 and 1934 Feng Youlan published first and second volumes of his "History of Chinese Philosophy". These outstanding works played a significant role in China's philosophical and historicalphilosophical thought and possess scientific potential even now, many years after the publication.

Both philosophers did not just expound the history of Chinese thought, but through the prism of the history of Chinese philosophy proof the very existence of it, and predicted its future development. Despite the similarities in their education, $\mathrm{Hu}$ Shih and Feng Youlan held completely different views on philosophy in general and the history of Chinese philosophy in particular. In this sense, these two "Histories" were not only pure scientific works but also focused on scientific ideals: $\mathrm{Hu} \mathrm{Shih}$, as advocate of westernization and Deweyan's instrumentalism was focused on the scientific criteria of philosophical research, still Feng Youlan as creator of new Confucianist doctrine - New Principle Learning (xin lixue, 新理学) - tried to support his concept by the idea of long-lasting history of Chinese Confucian thought.

$\mathrm{Hu}$ Shih conceived the "Outline of the History of Chinese Philosophy" as a multivolume edition. The first volume of "Outline" consists of 12 chapters and covers only the ancient Chinese philosophy from Lao Tzu to Xun Kuang. During his life, $\mathrm{Hu}$ Shih repeatedly promised to write a continuation, but "Outline of the history of Chinese philosophy" remained in one volume. Hu Shih's researches on issues related to the further history of Chinese thought - the philosophy of Buddhism, NeoConfucianism, etc. - remained in the form of separate articles.

"The History of Chinese Philosophy" by Feng Youlan is the first complete study of the history of philosophy in China. $\mathrm{Hu}$ Shih in a review of the English translation of the "History of Chinese Philosophy" wrote: "Professor Fung's work should be welcomed as the first, and only, full-size history of Chinese philosophy. Other pioneers in this field, including the late Liang Ch'i-ch'ao and myself, have not been able to complete their projected whole histories of Chinese thought or philosophy " [3. P. 898.]. "The History of Chinese Philosophy" is a two-volume work, numbering 1041 pages in Chinese and 1238 pages in the translation of Derk Bodde. The work begins with the presentation of the origin of philosophy in China and ends in the second volume with a presentation of the philosophical ideas of Liao Ping (廖平, 1852-1932) - a scientist-canonologist of the late Qing - early Republic period, who had great influence on Confucian reformer Kang Yuwei (康有为, 1858-1927).

\section{DEFINITION OF PHILOSOPHY}

From Hu Shih's "Outline of the History of Chinese Philosophy" immediately evident the changes that have occurred in the perception of philosophy in China since the publication of the "History of Chinese Philosophy" by Xie Wuliang. Speaking of philosophy and the Chinese sages $\mathrm{Hu}$ Shih freely uses the terms "philosophy" (zhexue, 哲学) and "philosophers" (zhexuejia, 哲学家). Without any further explanation or curtsey towards the Western origin of this term. Although it should be noted that when he speaks of the Chinese sages, he sometime also uses the term zhu zi (诸子), a traditional definition for the outstanding intellectuals of ancient China from the period of the Warring States to the Han Dynasty. Giving a definition of philosophy, he writes: "Any science that explores the most important issues of human life, and in the search for basic solutions reasoning from its origins, is called philosophy." [4. P. 7.]. In this definition, one can find a pragmatic focus on solving specific problems, a remarkable blurring of the line between science and philosophy, even more radical than that of Dewey, as well as the traditional Chinese "anthropological" orientation. Later, $\mathrm{Hu}$ Shih, refining his definitions, emphatically spoke from the point of view of instrumentalism: "Philosophy examines the most important issues of human life, comprehending them from the point of view of significance, and seeks significance that can be to a certain extent universal" [5. P. 281]. Noteworthy in this sense are explanations of $\mathrm{Hu}$ Shih, placing an emphasis on the ethical (in the scientific sense) component of philosophical creativity. If "ordinary people", according to $\mathrm{Hu}$ Shih, "either convince others to do well and not wrong, or encourage good deeds and punish the bad", then "philosophers, when meeting with similar problems, study what is "good" and "evil", find out the nature of "good" and "evil" [4. P. 7.].

Feng Youlan in the introduction to the first chapter of the "History of Chinese Philosophy" notes the western origin of the word "philosophy". In his opinion, an important stage in the work on the history of Chinese philosophy should be the choice and presentation of various teachings of Chinese thought that would correspond to the Western name of philosophy [6. P. 3]. Feng Youlan rejected to define the term "philosophy", because "the definitions of the "philosophy" of various philosophers differed ... knowing its content, one can know what philosophy is, and the official definition of the word philosophy is not necessary to be given specifically" [6. P.3]. Feng Youlan gives the content of the Greek philosophy (Physics, Ethics, Logic) and clarifies this content using contemporary terms as follows: a Theory of World, a Theory of Life, and a Theory of Knowledge [6. P. 3-4]. So, philosophy is thoughts of those thinkers who reasoned over issues related to the above framework of philosophy.

Feng Youlan makes special remark that the terms "Chinese philosophy" and "Chinese philosophers" are possible to use, because Western philosophy is similar in its content to xuanxue (玄学, learning of the mystery) of the Wei and Jin dynasties, daoxue (道学, learning of the truth) of the Song and Ming dynasties and the yilixue (义理学, learning of the principles) of the Qing dynasty [6. P. 6.]. Feng Youlan believes that in China since ancient times has been paid attention to issues that relate 
to the main divisions of philosophy: A Theory of World, and A Theory of Life (ethics and metaphysics - as it was translated by Bodde). As for A Theory of Knowledge, in his opinion, ancient Chinese philosophers reflected on these questions, but in the future these questions were mostly ignored.

Feng Youlan notes that in Western philosophy in each of the sections of philosophical knowledge we could see developed teachings, while Chinese philosophers have paid great attention to human problems and have been careless about cosmological and other studies. He notes that the views of Chinese philosophers in the field of methodology, argumentation and explanation are much inferior to Western and Indian philosophies [6. P. 7]. But this happened, according to Feng Yulan, not because of the inability of Chinese thinkers to develop the methodology, but because of inattention to it. He explains this by the fact that knowledge was of interest to Chinese philosophers not in as clear knowledge itself, but as an instrument that could lead to happiness. Feng Youlan believes that Chinese philosophy was interested in the question "what is a person" and not "what does a person have", so interested in the moral qualities of a person, and not in his intellectual indicators. "If a man a Sage, he remains a Sage, even if he is completely lacking in intellectual knowledge; if he is evil man, he remains evil, but he may have boundless knowledge"[7. P. 2].

In spite Hu Shih has the label of the "Westernizer", he in his work practically does not make references to the West, to the western origin of philosophy, etc. He builds his exposition on the basic axiom that philosophy is a universal phenomenon existing in similar forms in the West and the East. His presentation of the history of Chinese philosophy is based on Western scientific standards, but he does not differentiate approaches to Western and Chinese philosophy.

While Feng Youlan still regularly looks back at the West, explaining that, despite all the features, Chinese philosophy is a philosophy.

\section{ON THE SENIORITY OF LAO TZU OR CONFUCIUS}

An important issue in the development of the history of Chinese philosophy was a vivid discussion in the Chinese philosophical circles in the 1920 s about the seniority of Confucius or Lao Tzu. One of the reasons for the discussion was Hu Shih's "Outline of the History of Chinese Philosophy." $\mathrm{Hu}$ Shih in his work sought to show that Confucianism was one of the equal philosophical schools of Ancient China, while Feng Youlan in every possible way emphasized the priority position of Confucianism from the very moment of its inception.

Sharp discussions about the life of Lao Tzu lasted for about ten years. In addition to $\mathrm{Hu}$ Shih and Feng Yulan, other philosophers of that time participated in it, including Liang Qichao, Gu Jiegang, Luo Gengse, Qian Mu and others.

Responding to opponents who said that "Dr. Hu Shih is too old-fashioned" and departed from the ideas of progress, about which he himself spoke so much", the scientist refused to recognize the dates that are shifting the period of life of Lao Tzu and, accordingly, the creation of "Tao Te Ching" for several centuries closer to the turn of the century AD. He strongly accused his opponents of superficiality: "Those who do this have not thoroughly studied this question" [8. P. 759]. $\mathrm{Hu}$ Shih repeatedly stressed his willingness to change his views, but only on the condition that he was provided with "sufficiently convincing" materials. In 1933 he declared: "So far, there have been no such materials, so my view of this issue remains conservative" [8. P. 749]. Subsequently no one succeeded in convincing him.

Especially hot debate broke out between Hu Shih and Feng Youlan. Both philosophers up to the last years of life firmly adhered to each of their positions.

Thus, in 1931, when Feng Youlan's "History of Chinese Philosophy" was published, the author sent a copy to his former teacher $\mathrm{Hu}$ Shih. In reply letter (published on June 8 1931 г. In "Dagong bao. Wenxue fukan”, № 178), thanking for the interesting book, he sharply criticized the opinion that Lao Tzu created "Tao Te Ching" in period of Warring States (475$221 \mathrm{BC})$.

None of the evidence given by Feng Youlan in defense of this thesis did not satisfy Hu Shih. He wrote that in the dating of the life of Lao Tzu and the time of writing of "Tao Te Ching" Feng Youlan adheres to the vicious approach, according to which "the evidence requiring proof is already contained in the premises" [8. P. 749].

In a letter to Feng Youlan $\mathrm{Hu}$ Shih criticized him for identification of "Lao Tzu and Taoism," as Feng argued the late appearance of the "Tao Te Ching" by relatively late forming of holistic Taoist belief system. Hu Shih quite sharply reproached him: "[The name]" Taoism" arose after the Qin [dynasty] ... In the times of Lao Tzu and Chuang Tzu no one called them Taoists. Therefore, this reason [the emergence of Taoism] is not sufficient to delay the emergence of "Lao Tzu" for a later time "[8. P. 744].

Analyzing the evidence of their opponents - Liang Qichao, Feng Youlan, Gu Jiegang and others, Hu Shih emphasizes the danger of the truth-seeking research method used by them - in his words, the method of "systems thinking" (sixiang xitong, 思 想系统) or "line of thinking" (sixiang xiansuo, 思想线索), meaning by this systematic and consistent execution of a certain sequence of analytical operations. "You can say that I myself made this method "exemplary", therefore I must bear some responsibility for this" [8. P. 750]. Hu Shih thought that this kind of methodicalness makes the study excessively dependent on the sum of the initial attitudes and preferences: "This method is very dangerous. it is unable to avoid a subjective view, it like a double-edged sword, can cut in both directions. If your views are inclined to the east, this method will help to move to the east, if the views are inclined to the west, it will help to move to the west" [8. P. 750].

As an example of such subjectivity, $\mathrm{Hu}$ Shih gave two versions for analyzing the 15th chapter of "Analects". As he noted, on the basis of the phrase "govern by non-action" (XV.5), two opposite conclusions can be drawn. The first, to which $\mathrm{Hu}$ Shih came himself, is the possibility of "proving that Confucius was under the influence of Lao Tzu" [8. P. 751.]. However, Gu Jiegang and others quite "systematically" on the 
same basis came to the opposite conclusion: "The ideas from "Analects" were actively used in "Lao Tzu" [8. P. 751].

One of the strongest proofs of the early creation of the "Lao Tzu" Hu Shih saw in the phrase from the 25th chapter of "Tao Te Ching": "I do not know how to call it. Giving it the nickname, I will say: "Tao". If I have to give him a name, I will say: "Great". Hu Shih believed that these words gives "clear proof" that Lao Tzu "first came to this great view, and [earlier] there was no suitable name for [Tao-Absolute]. It was worth the effort to call it the Way, or [through the metaphor] of the external form to call "great" [9. 746]. Such views were not easy to gain recognition, and only by the end of the Warring States period they became the central ideological conception [9. P. 747].

Many years later, Hu Shih turned his attention to this longstanding discussion again $\mathrm{n}$. In the preface to the Taiwanese edition of "The History of Ancient Chinese Philosophy" (1958) (it was new name for "Outline of the History of Chinese Philosophy"), he wrote that he had finally understood what his opponents were guided by in a long-standing dispute. "The question of the time of life of Lao Tzu was not at all a question of a demonstrative method. This was originally a matter of religious faith. Scientists like Feng Youlan believed that Confucius was a patriarch, the pioneer of Chinese philosophy ... and, of course, with such a religious faith there could not be any Lao Tzu before Confucius ... Then I realized that the article I wrote 25 years ago, "Criticism of modern methods dating "Lao Tzu" was a senseless and fruitless waste of effort "[10. P. 9]. Let's add that $\mathrm{Hu}$ Shih himself in this discussion was not always a model of objectivity and impartiality.

The dispute about the life of the founder of Taoism and the seniority of Lao Tzu or Confucius has not ended so far. In our time there is no unity in this issue. Some researches begin the exposition of Chinese philosophy with Lao Tzu, others with Confucius, the third with the semi-legendary Xia dynasty (end of III millennium BC - XVII century BC). But now these disagreements are mostly academic in nature and to a much lesser extent fueled by ideological preferences.
In the beginning of 20th century, the solution of the question of which of the two thinkers (Lao Tzu or Confucius), was older became equal to the definition of the very beginning of the Chinese philosophical tradition.

\section{CONCLUSION}

Chinese philosophy has a thousand-year history, but it acquired its modern form in the early 20th century. The works of $\mathrm{Hu}$ Shih and Feng Youlan laid the foundation for a modern understanding of the heritage of ancient Chinese thought. They proposed the use of the Western model of rationality to expound the ideas of Chinese thinkers of antiquity. Not everyone agreed with them. They were criticized by representatives of conservative circles, and Marxist historians of philosophy. But the role played by their works in the further development of Chinese thought is unquestionable.

\section{REFERENCES}

[1] Hegel G.W.F. Lectures on the History of Philosophy, Vol. 1. London: Kegan Paul, Trench, Trubner \& CO., Ltd, 1892.

[2] Xie Wuliang. History of Chinese Philosophy (Zhongguo zhexueshi). Taipei: Taiwan zhonghua shuju, 1976. P. 6.

[3] American History Review, Volume 60, Issue 4, 1 July 1955.

[4] $\mathrm{Hu}$ Shih. Outline of the History of Chinese Philosophy (Zhongguo zheksueishi dagang). Shanghai: Guji Chubanshe, 1997.

[5] Hu Shih. Philosophy and Human Life (Zhexue yu rensheng) // Collected works of $\mathrm{Hu}$ Shih (Hu Shi Wenji). Vol. 12. Beijing: Beijing daxue chubanshe, 1998

[6] Feng Youlan. History of Chinese Philosophy (Zhongguo zhexueshi) Vol. 1. Chongqing: Chongqing chubanshe, 2009

[7] Feng Youlan., A History of Chinese Philosophy, Vol. 1. Princeton University Press, 1983.

[8] Hu Shih. Lao Tzu is older than Confucius (Lao-zi bi Kong-za hailao) // Science works by $\mathrm{Hu}$ Shih - History of Chinese Philosophy ( $\mathrm{Hu}$ Shi xueshu wenji- zhongguo zhexueshi). Changchun: Jilin renmin chubanshe, 2003.

[9] Hu Shih. Discuss "Lao Tzu" with Mr. Qian Mu (Yu Qian Mu xiansheng lun «Lao Tzu»// Science works by Hu Shih - History of Chinese Philosophy (Hu Shi xueshu wenji- zhongguo zhexueshi). Changchun: Jilin renmin chubanshe, 2003.

[10] $\mathrm{Hu}$ Shih. Foreword for Taipei edition of "The History of Chinese ancien Philosophy" ("Zhongguo gudai zhexueshi" Taibei ban ziji // Selected works by Hu Shih (Hu Shi xuanji). Changchun: Jilin chubanshe, 2005. 